Document downloaded from:

http://hdl.handle.net/10251/65059

This paper must be cited as:

Alcázar-Ortega, M.; Calpe Esteve, CM.; Theisen, T.; Rodríguez-García, J. (2015).

Certification prerequisites for activities related to the trading of demand response resources. Energy. 93:705-715. doi:10.1016/j.energy.2015.09.082.

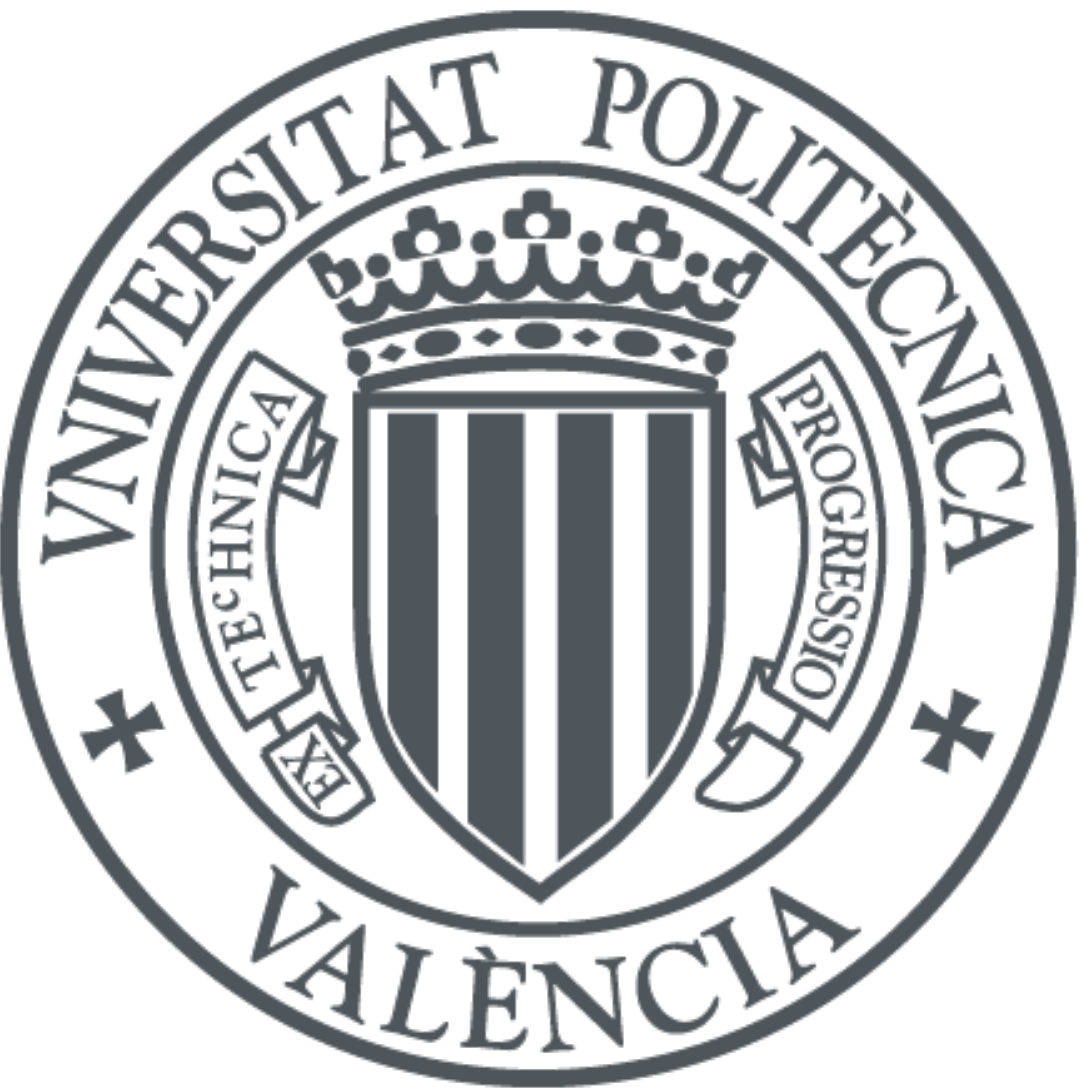

The final publication is available at

http://dx.doi.org/10.1016/j.energy.2015.09.082

Copyright Elsevier

Additional Information 


\title{
Certification prerequisites for activities related to the trading of Demand Response Resources
}

\author{
Manuel Alcázar-Ortega ${ }^{\mathrm{a}, 1,2}$, Carmen Calpe ${ }^{\text {a }}$, Thomas Theisen ${ }^{\text {a }}$, Javier Rodríguez-García ${ }^{\mathrm{b}}$ \\ ${ }^{a}$ RWE Deutschland AG, Department of New Technologies, Kruppstraße 5, 45128 Essen, Germany \\ b Universidad Politécnica de Valencia, Institute for Energy Engineering, Camino de Vera, s/n, edificio 8E, \\ escalera $F, 5^{a}$ planta, 46022 Valencia, Spain
}

\section{Keywords}

Demand response; certification; renewable integration; industrial production; aggregation; load management

\begin{abstract}
Certification according to international standards brings many benefits to the society, including technical, economic and environmental aspects. In this context, this paper highlights the benefits of certification of Demand Response, including the additional credibility which provides to the trading of flexibility and higher confidence between different players. The consequence is a dynamic environment which facilitates the market acceptance of Demand Response services and products, providing significant benefits to providers and users of such services. A methodology for the systematic certification of different activities related to the transaction of Demand Response resources has been developed and it is presented here. In particular, three types of certificate have been specified, considering the certification of the entity providing the resource (Demand Response Provider), the contractual framework between the provider and the requester (Demand Response Product) and the physical platform to enable and guarantee such transaction (Demand Response Energy Service Trader).

\footnotetext{
${ }^{1}$ Corresponding author. E-mail addresses: manuel.alcazar-ortega@rwe.com (M. Alcázar-Ortega), carmen.calpe@rwe.com (C. Calpe), Thomas.Theisen@rwe.com (T. Theisen), jarodgar@iie.upv.es (J. Rodríguez-García)

2 Present address: Universidad Politécnica de Valencia, Institute for Energy Engineering, Camino de Vera s/n, edificio 8E, escalera F, 5 a planta, 46020 Valencia, Spain. E-mail address: malcazar@iie.upv.es
} 
The results of this paper may help regulators and standardization bodies in the design and specification of a future norm to allow the certification of the above-mentioned activities, or a further development of existing regulation for certification of energy efficiency systems (like ISO 50001), where certification of Demand Response activities could be complementary.

\section{Introduction}

Demand Response (DR) represents an adequate option for reserve capacity in the context of increasing wind power generation and usage, which is characterized by its variability and unpredictability [1]. The promotion of electricity from renewables is a key European Union priority for several reasons, including the security and diversification of energy supply, environmental protection and social and economic cohesion. In other countries, like the United States state governments and federal initiatives such as the production tax credit and others have promoted the growth of renewables [2]. Also in Australia, some research has demonstrated that wind power producers can employ DR to maximize its profit [3]. However, the expansion of renewable energy sources requires new means of load management and greater quantities of various ancillary services [4]. Whereas conventional energy fuels can be converted whenever needed, renewables cannot. Wind and solar power generation depend on external conditions and their supply is not directly controllable. In this context, DR aims at adjusting the electricity demand to the grid requirements at a given point of time, which make it an important pillar in the context of Smart Grid concepts for achieving the EU's 20/20/20 goals, contributing to increase the efficiency of the power system [5].

Different provisions dealing with demand side participation have been included in various EU policy documents, specifically the Electricity Directive (2009/72/EC) and the Energy Efficiency Directive (2012/27/EU). On the other hand, a large potential of DR resources have been identified in Europe [6]. However, as stated by [7], the market designs and policies in place in most of the European countries do not promote today the participation of demand in electricity markets. On the contrary, DR and related activities such as aggregation remain illegal in many of them and in the majority of system services and wholesale markets [8].

DR has proven to be a useful mechanism that produces significant benefits for both the customer and the power system [9-13]. Thus, customers may enrol in some DR program, designed and implemented by energy suppliers and network operators. These programs may provide a profitable 
option for customers that modify their usual pattern of consumption as response to an external event. On the other hand, system operators or utilities can use DR to curtail or shift loads instead of just building more infrastructures for generation or energy storage, which provides significant cost savings in close to real time, often at lower cost than generation resources [14]. However, DR does not happen naturally and it needs mechanisms to be stimulated [15].

The certification of the different activities involved in the transaction of DR resources would add credibility to the trading of flexibility, increasing the dynamism of the market and the confidence between the different players, facilitating the market acceptance of DR services and products. Nowadays, certification based on international standards has become a strategic tool to ensure that business operations are as efficient as possible, increasing the productivity and helping companies to access new markets [16].

Some efforts have been done in order to create some kind of norm to allow the certification of DR, especially in the US. Previous research has identified the need to develop standards to integrate and enable buildings to participate in Smart grids [17]. According to this interest, the Laurence Berkeley National Laboratory (LBNL) designed the Open Automated Demand Response (OpenADR) [18], which represents the only standard existing in the World related to DR, even if it is only applied to communication purposes for commercial buildings [19]. Nevertheless, an international norm to allow the certification of the different activities related to the trading of DR resources is still missing. Energy efficiency systems can be certified according to the standard ISO 50001 [20] and, based on this fact, several European countries offer financial instruments to promote the adoption of more efficient technologies and particularly, the utilization of renewable energy resources [21]. Nevertheless, due to the lack of a norm or standard for this purpose, DR cannot be certified by now even when energy management has been identified by ISO as one of the top five areas that require the development and promotion of international standards [22]. Therefore, this paper proposes a methodology for the systematic certification of different activities related to the transaction of Demand Response resources. This methodology has been designed in the framework of the European LIFE+ Project "Demand Response in Industrial Production".

The paper is organized as follows: Section 2 provides some basic concepts about Demand Response, the way how Demand Response actions can be classified and the reasons why it is necessary nowadays for the proper operation of power grids. Section 3 describes the roles and 
considered scenarios which frame the resulted methodology for certification of DR activities, detailed in Section 4. The further implementation of the proposed methodology and its limitations are discussed in Section 5 where the next steps for its application are highlighted. Finally, conclusions of this research are presented in Section 6.

\section{Demand Response overview and its benefits}

\subsection{What is Demand Response?}

The concept of DR is understood as the ability of consumers to modify the power demand from their expected consumption either as a response to a requirement from the grid operator, load-serving entity (LSE) ${ }^{3}$ or other demand response provider when a reliability problem occurs in the system, or as a reaction to variations in the price of electricity. While DR actions can take place at any time, not only during the peak period [23], their implementation could be key during peak periods of electricity use, and they are usually less costly than building more power plants [24].

Depending on how Demand Response actions are performed, the different actions can be divided into three blocks, as shown in Figure 1 [9]:

- Demand shifting by moving some energy packages from some periods (usually on-peak to shoulder or valley periods) when electricity is cheaper or the operation of the grid is less critical. This is the most frequent type of demand response action, which takes place in the industry. The net balance in the energy consumption may be zero, but the economic benefit achieved by the customer is positive, as the price of electricity is different during those periods.

- Demand reductions (or increases), which are not compensated by rises (or reductions) during the rest of the time. A typical example is lighting, which if reduced, it is not later reconnected to recover the consumption. These actions imply a loss of service, which may be translated into loss production and extra cost.

- Autonomous self-generation, producing the electricity that customers use onsite, which translates to a net reduction of the demanded power from the grid with no load modifications required from the consumer.

\footnotetext{
${ }^{3}$ Load-serving entity (LSE) collectively refers to utilities and competitive retail suppliers [14]
} 
The planning, implementation and monitoring of activities designed to encourage consumers to modify patterns of electricity usage is known as Demand Side Management (DSM) [25]. DSM and load management strategies have been commonly used in the operation of electricity systems for more than 30 years in such countries like the United States [26]. However, DR resources have been underutilized in other regions like Europe, where the absence of initiatives on demand response, which now arise, could have been motivated by the inexistence of a single European energy market [7].

Today, DR is becoming more automatic and easier to implement for customers since electricity prices and similar information can now be automatically delivered and because communication technology is more accessible [27]. System operators can therefore allow customers to participate in different DR alternatives. Since the year 2000, in both the USA [28], [29] and Europe [30], [31], different research has been carried out in order to develop new DSM programs which involve commercial and residential customers (and not just large industrial ones like it was common in the past) in the operation of the electricity systems.

\subsection{Benefits of Demand Response}

DR is an important pillar in the context of Smart Grid concepts and it can contribute significantly to achieving the 20/20/20 goals. DR has been also identified as key to delivering an affordable and climate-friendly energy system by the Expert Group on Regulatory Recommendations for Smart Grids Deployment (EG3) [32] in a lately published report, where the need of more flexibility to ensure that the energy system is able to cope with the future challenges is enhanced.

Electric power systems have the following characteristics [14]:

- Electricity cannot be stored in large amounts economically, what means that supply and demand must be balanced at any time.

- Grid conditions can change significantly very quickly and unexpectedly, resulting in mismatches in supply and demand, which can jeopardize the power system quite fast. This is especially true nowadays when the implementation of new renewable resources of generation (especially wind power) has shot up. It means a notable increase in the variability and unpredictability of the generation and the consequently more expensive management of the grid. The use of flexibilities like demand response may help to reduce the grid expansion costs. 
- The ongoing "energy transition" increases the need for flexibility as it will be more and more necessary that the demand follows supply (at least in critical situations) and not vice versa as the system works most often today.

- Central generation and transmission system investments have long lead times and cannot be extended in smaller steps. This kind of investment is only efficient if a high capacity increase is necessary.

Due to these characteristics, power systems need to be planned and managed for years in advance in order to guarantee that the system can operate reliably in real time despite the many uncertainties on future demand, fuel sources and asset availability.

These challenges, linked to the abovementioned uncertainties of the grid, make DR so valuable for the power system. System operators or utilities can use Demand Response to curtail or shift loads instead of just building more infrastructures for generation or energy storage. Thus, DR can produce significant cost savings in close to real time, often at lower cost than generation resources $[11,14]$. The most recent efforts on DR issues are related to the use of flexibility for the operation of Smart Grids and the new challenges of the electrical networks such as the integration of electrical vehicles and storage devices. An example of application of DR concepts for the optimal operation of a distribution company considering energy storage, renewables and electrical vehicles is described in [33]. Fast power DR strategies based on the use of DR resources for smart grid applications are discussed in [34]. Some examples about strategies which can be used by end-users to take advantage of their electric devices for DR purposes can be found in [35-37], specially focused on control applications for acclimatization devices. Finally, some research such as [38] and [39] is focused on the identification of market barriers which prevent the massive utilization of DR resources. This last reference concludes that one significant barrier is the lack of an international standard to allow the certification of the different activities involved in the trading of DR resources.

Summarizing: DR aims at adjusting the electricity demand to the grid or system requirements at a given point of time and thereby facilitates the further integration of distributed energy resources, improving the efficiency of the whole electricity system. 


\section{Roles and considered scenarios for Demand Response trading}

This section describes the scenarios considered for certification purposes, including the definition of the involved stakeholders, their role in the trading of DR resources and how they are related to each other.

\subsection{Roles in Demand Response trading: definitions and linking}

As in the trading of any service or good, the two main actors in the interchange of DR resources are the agent who is requiring the product or service and the agent who is providing the first one with the product or service. The agent who is providing DR resources will be nominated as Demand

Response Provider (DRPV). On the other hand, the agent who is requesting the DR resources to the DRPV will be called Demand Response Requester (DRRQ).

The trading of DR resources necessarily includes a physical mean by means of which DR can be delivered. Moreover, the terms of the interchange must be described in some kind of agreement where such characteristics as the description of the product, how it will be traded and the settlement procedure should be clearly stated.

The contractual framework which guarantees that the service provided by the DRPV satisfies the minimum requirements of the related service to the final user or DRRQ will be called Demand Response Product (DRPR).

Complementarily, the agent responsible to physically support the delivery of a DR service between a DRPV and a DRRQ will be called Demand Response Energy Service Trader (DREST). These roles are represented in Figure 2.

A DRPV can be an energy consumer (also called "customer") offering some amount of flexible power as a result of a modification in the usual pattern of energy consumption, but they can also be aggregators offering complex demand packages to other agents. On the other hand, DRRQs will be usually transmission and distribution system operators (TSO/DSO) or retailers, which would be final users of the service provided by DR; however, also aggregators looking for smaller demand packages to build more complex offers could behave as DRRQ. Therefore, depending on the direction of the trading of DR resources, aggregators could be both DRPVs and DRRQs, as shown in Figure 3. Therefore, industrial customers would be typically providers of DR. Together with them, Energy Service Companies (ESCO) would play an essential role here in order to support customers in the identification of flexibility and the assessment of potential benefits. 
Transmission system operators (TSO), distribution system operators (DSO) and retailers would be final users of DR resources and thus, requesters of DR services to the providers (DRRQs) Aggregators could be DR users when requiring DR services from customers (or other aggregators), but they can be also DR providers for a third party (a final user as a TSO/DSO, or even another aggregator as a new intermediary)

Two new stakeholders and consequently two business opportunities arise:

- The developer of DR Products or contractual models to facilitate the trading of DR resources

- The Energy Service Trader as provider of a platform to support the physical interchange of $D R$ resources.

\subsection{Types of scenario}

DR transactions between an energy consumer or customer as "creator" of DR and a final user of a DR service will be called "Direct Trading". Conversely, DR transactions through aggregators will be called "Indirect Trading". These two scenarios are represented in Figure 3.

A complete transaction between a customer and a final user of a DR service may involve different indirect transactions. In this case, aggregators may play the role of DRRQ at one side and DRPV at the other side.

For each scenario, the economic transactions among the involved agents should be established in their contract. A DRRQ would have to pay to a DRPV for the service that the last gives to the first. The intermediary parts (DRPR and DREST) should be jointly and severally paid by the DRPV and the DRRQ, although the part of the DRPV could be discounted in the final price settled by the DRRQ. In case of indirect trading, the situation is similar: when the aggregator behaves as DRRQ, it would give a payment to the consumer as DRPV, taking also into account the previous considerations regarding intermediaries. On the other hand, when the aggregator behaves as DRPV it would receive a payment from the other side (TSO/DSO, retailer or other aggregator in the role of DRRQ) which would be independent on the payment given to the customer in the previous transaction.

\subsection{Types of certificate}

The method here presented establishes certifications which would be applicable to the abovementioned roles in the transaction of DR resources. However, as it has been said, there is not a 
norm which currently allows the certification of DR services. Consequently, this document may be taken by regulators and standardization bodies in the future as the foundation of a certification prerequisites procedure.

In this context, three activities have been considered susceptible to be certified:

- $1^{\text {st }}$ type: Certification of Demand Response Providers (DRPV)

- $2^{\text {nd }}$ type: Certification of Demand Response Products (DRPR)

- $3^{\text {rd }}$ type: Certification of Demand Response Energy Service Traders (DREST)

The characteristics which should have each of these certificates are described in the next section.

\section{Certification prerequisites for Demand Response activities}

\subsection{Method and justification}

According to the International Standard Organization (ISO) ${ }^{4}$, the certification is the "provision by an independent body of written assurance (a certificate) that the product, service or system in question meets specific requirements. In other words, a certification is a document which guarantees that a product, service or process satisfies some kind of norm or standard". Nowadays, certification based on international standards has become a strategic tool to ensure that business operations are as efficient as possible, increasing the productivity and helping companies to access new markets. Certification according international standards may bring many benefits to the society, including technical, economic and environmental aspects. Standardization helps customers to trust that products are safe, efficient and good for the environment. In some cases, certification is even a legal or contractual requirement.

As stated by ISO, the main benefits provided by standardization include:

- Cost savings, as operations are optimized and the final result is improved.

- Customer satisfaction is enhanced, as standardization improves quality, which may increase sales.

- Access to new markets, as standards help to prevent trade barriers, which enable customers to participate in global markets.

- Increased market share, as they may increase productivity and competitiveness.

\footnotetext{
${ }^{4}$ More information can be found in the website of the International Standard Organization: http://www.iso.org
} 
- Environmental benefits, as negative impacts on the environment are prevented.

As it was mentioned above, improved energy efficiency systems can be certified according to the standard ISO 50001. There are also standards for the certification of the process of energy auditing related to Energy Efficiency (ISO 50002 or EN 16247). However, there is not a norm or standard for the certification of Demand Response (DR) and, consequently, DR cannot be certified by now. Nevertheless, the certification of the different activities involved in the trading of DR resources arises as an essential mechanism for the stimulation of the demand side for the massive utilization of this kind of resources, with the subsequent benefits detailed in the previous chapters.

The methodology here proposed was designed during the DRIP project. This project started in September 2012 and took 30 months for its completion, which took place in February 2015. During those 30 months, a complete review of the state-of-art of DR in different countries (especially in Europe and the US) was done, and the activities involved in the trading of DR resources were identified and classified, as it is detailed in section 3. The methodology here presented is the result of an iterative procedure where more than 50 stakeholders have participated, representing the different market roles under study (industrial and commercial customers, DSOs, power producers, energy services companies (ESCOs), retailers, experts on energy regulation, certifiers and aggregators). Since certification is not possible today due to the lack of a norm or standard (as mentioned above), a previous "prequalification" stage took place where the basis of the methodology were established. Finally, a roadmap for the further development of a norm or standard to allow the certification of DR activities was defined, as discussed later in section 5 .

\subsection{Certification of Demand Response Providers (DRPV)}

In the case of providers of DR resources, the certificate must guarantee that the DRPV is flexible, in which amount and under which conditions the flexibility exists, as well as that the required equipment for control, monitoring and measurement is installed and ready to be used.

These aspects need to be verified by means of testing, based on a standardized and repeatable procedure.

In case of customers as DRPVs, a previous study and detailed evaluation of their flexibility is necessary. For aggregators, this evaluation of flexibility is not necessary because the complex offers they can design and sell as DRPVs have been built by combining demand packages already flexible 
(e.g. they have been bought to customers certified as DRPV), so that they should directly do the testing phase.

An important point of this approach is that DRPVs would not be not certified in abstract, but based on a set of particular flexibility actions which have been previously evaluated. So, a certified DRPV could offer to the market a standard demand package as it is specified in the certification document.

Standard demand packages are called here "standard" because they are defined in base to standard parameters (specified in section 4.2.1) but not because they should fit in some kind of pre-established DR program. This is an essential difference between this approach and how DR has been traditionally considered. In this way, the full potential of customers can be used as they get a certification based on their real abilities and not on how well they fit in some existing DR product.

Once the evaluation of flexibility has been done and the required equipment has been installed, a testing phase will validate the ability of the DRPV according to the defined DR actions.

\subsubsection{Standard parameters which define the flexibility}

An essential phase in the certification process is the standardization of the parameters which define any kind of flexibility based on which DR services may be traded. These parameters would be used by the DRPV to find out a proper DRPR in order to offer the flexibility to some interested DRRQ.

Consequently, these parameters must be the same in both types of certificate.

These parameters, represented graphically in Figure 4 for a standard load curve, are the following:

- Flexible power $\triangle \mathrm{PR}_{1}:$ This is the amount of power to be decreased or increased during the flexibility action. Depending on the service provided and also on the country, the minimum flexible power required to participate in the current DR services could be quite high (for example, the minimum required capacity for tertiary reserves in Germany is $15 \mathrm{MW}$ ). However, the flexible power offered by the customer could be lower than the minimum requested to participate as a single DR provider if the DR product is offered by an aggregator that could make a larger offer to the market by grouping different DR providers.

- Duration of the action $T_{D}:$ This parameter represents the time during which the interruption or increment of power is kept. As in the case of flexible power, current products may limit the participation of customers due to the exhaustive conditions applicable to single customers interested in providing some kind of DR service. Aggregators could solve this limitation and shorter actions could be offered. 
- $\quad$ Notification in advance TIA: This is the reaction time for the DRPV between the activation of the service as a requirement of the product buyer and the actual provision of the flexibility. As the minimum flexible power, this parameter depends on the service to be provided and also on the country. However, like in the case of the other parameters, aggregators could handle different offers in order to build the proper flexible package even if the single components of such offer do not individually fulfill this limitation. It is important to point out that the notification in advance is the time required by the DRPV since the reception of the requirement from the $\mathrm{DRRQ}$ up to the committed amount of power has been completely delivered. Consequently, the TIA includes the time required for preparation (power ramp, adaptation of consumptions, etc.).

- Extra power before the flexibility action $\triangle \mathrm{PR}_{2}$ : This parameter represents the maximum power demanded by the customer before the flexibility action in order to prepare its facilities.

- Extra power after the flexibility action $\triangle \mathrm{PR}_{3}:$ Similarly to $\Delta \mathrm{PR}_{2}$, this parameter represents the power demanded by the customer after the flexibility action in order to recover the initial conditions.

- $\quad$ Duration of the preparation $T_{P R}$ : This is the time during which the customer will demand $\triangle P R_{2}$ before the flexibility action in order to prepare its facilities.

- Duration of the recovery period $\mathrm{T}_{\mathrm{RC}}$ : This is the time during which the customer will demand $\Delta \mathrm{PR}_{3}$ after the flexibility action in order to recover the initial conditions.

- Operation times $T_{a v}:$ This parameter defines the time frame during which the service could be requested. The time frame definition should include:

- The days in which the action can be performed

- Starting and final hours of availability during the considered days

- Minimum time between interruptions TMIN: This parameter represents the time that must pass between the end of a flexibility action and the beginning of the next one, including the $T_{1 A}$. Consequently, $\mathrm{T}_{\mathrm{MIN}}$ must be equal or higher than $\mathrm{T}_{\mathrm{PR}}+\mathrm{T}_{\mathrm{RC}}$

- Link between flexibility actions: Other actions which may be affected by the activation of the considered flexibility action -including the preparation, duration and recovery period- will be indicated. A little explanation on how other actions may be impacted would be necessary. 
- Delay in the recovery period: The possibility to delay or schedule the recovery period after the performance of a flexibility action will be specified, detailing the time at which the recovery would take place.

\subsubsection{Other contents of the DRPV certificate}

In addition to the parameters mentioned before, information such as the methodology to calculate the baseline and the installed metering, control and monitoring equipment should be also included in the certificate.

The baseline of a consumer, which indicates the load profile that it would have if the flexibility action had not been activated, should be also included in the certification. The algorithm to calculate the baseline of the considered process must be clearly established, including the definition of all the used variables and indications on how to proceed in case of lack of some information. Thus, the effect of a flexibility action (reduction or increment of power) as well as the impact of preparation and recover periods would be evaluated as the difference between the real load curve and the baseline. For that reason, the calculation of the baseline must be as accurate as possible, and it will depend on the type of process that is considered.

On the other hand, the adequate implementation of flexibility requires the availability of the proper metering, control and monitoring equipment. Therefore, the following equipment should be, as minimum, installed in the facility to be certified:

- Metering system which used to verify the performance of the flexibility action

- Control system which will be used to perform the flexibility action. This equipment depends on the speed of response (e.g. an activation faster than 30 seconds would be required for the participation in secondary reserves)

In addition, the customer must have the ability to properly communicate with the agent who is requiring the application of the flexibility action. However, DRPVs would not need to have installed this equipment if they sign an agreement with a certified DR Energy Service Trader (DREST) as described in section 4.4 .

\subsection{Certification of Demand Response Products (DRPR)}

The need and convenience of developing standardized DR products has been already identified in previous research [8]. A certified DRPR provides confidence to the market agents who require some 
kind of DR service, so that a DRRQ (TSO, DSO, utility, aggregator, etc.) using a certified DRPR can ensure that using this contractual framework the DRPV is able to successfully perform the corresponding flexibility action under the conditions defined.

DRPRs would be used when a market agent different from the energy consumer receives a benefit from the DR flexibility of the energy consumer (e.g. when DR is used by a DSO to increment capacity reserve in his operation area or by a retailer to balance his portfolio), so that this market agent is willing to pay to the customer for this service. The customer may thus benefit from such payment in addition to other complementary benefits coming from the use of flexibility according to the prices in the own contract (Time-of-use contracts, real time prices, etc.).

DRPRs have been traditionally developed by the final users of DR services, such as TSOs and utilities [9]. However, the development of standard DRPRs is a new business which could be performed by an independent entity. It means that the final users of DR services can develop their own DRPR, or they could use standard products developed by some kind of external entity.

\subsubsection{Standard parameters}

As stated in 4.2.1, the standard parameters considered for the certification of standard DR products would be basically the same as considered for the certification of DR providers in order to allow DRPVs to find and choose a proper DRPR.

In case of the parameter "Flexible Power" denoted in section 4.2.1 as $\Delta \mathrm{PR}_{1}$, it could be lower than the minimum requested by DRRQs if the DR product is offered by an aggregator that could make a larger offer to the market by grouping different DR providers. Consequently, this is not a limiting factor for the certification of DRPRs since flexible demand packages so defined could be used by aggregators to build complex offers which may satisfy such minimum requirements. An example of this aspect is presented in Figure 5 where a complex offer has been created by combining four different offers based on certified DRPRs. Considering $\mathrm{TIA}_{1}$ as a very short notification in advance (e.g. 30 seconds), $\mathrm{DRPR}_{1}$ and $\mathrm{DRPR}_{2}$ are fast products which could be quickly activated. However, they are not long enough so as to guarantee the suitability of these products in any operation service. On the other hand, products $\mathrm{DRP}_{3}$ and $\mathrm{DRP}_{4}$ need a longer notification in advance so their use alone for operation services is limited. Nevertheless, considering the four products together, a complex offer could be designed by an aggregator so that products $\mathrm{DRP}_{1}$ and $\mathrm{DRP}_{2}$ would guarantee a fast activation of the service while $\mathrm{DRP}_{3}$ and $\mathrm{DRP}_{4}$ will provide it with a longer duration of the flexibility action. At the same 
time, the simultaneous combination of more than one of these blocks would enable the aggregator to create larger offers which may be more attractive for a DR requester (in the example, the total amount of power $\mathrm{P}_{2}$ in the complex offer is a combination of the individual capacities).

Similarly to the flexible power, the duration of the flexibility action $T_{D}$ and the notification in advance TIA should not mean a limitation for the certification of DRPRs. Aggregators can use offers which individually does not satisfy the minimum required duration or notification for an operation service (e.g. an aggregator can use the fastest DRPRs to create a quick response product combined with slower DRPRs to offer such product for longer) if they can build a complex offer according to the minimum requirements of the services requested by DRRQs even if individual offers do not satisfy such requirements.

\subsubsection{Other contents of the DRPR certificate}

In addition to the standard parameters previously stated, there is other kind of technical information which not being directly related to the definition of the flexibility actions provided by DRPVs is essential in order to completely define the requirements of DRPRs. Such parameters are:

- Mode of activation of the service, which could be manual or automatic. The mode of activation depends on the type of service given by the DRPV. For example, secondary reserves require immediate response (e.g. 30 seconds in Spain), that makes necessary automatic call to the customer.

- Flexibility strategy. There are two basic ways to implement a flexibility action: Firm power level (the consumer guarantees that the maximum power by him demanded will never overcome the value indicated in the contract during the action) or flexible power (the consumer guarantees a reduction during the action equal to the difference between the real consumption during the action and the baseline)

- $\quad$ Recovery strategy. According to the time when the recovery of the energy shifted during the flexibility action would be done, there are two strategies: Immediate recovery (the recovery period starts just when the flexibility action finishes) or flexible recovery if the consumer can delay the starting time for the recovery period.

- Measurement and communication requirements. Such requirements will depend on the type of service provided by the DRPV. Some relevant standards used in the European network by TSOs are described in [40] and they could be considered here. Metering requirements include 
the measurement cycle, the minimum accuracy of the measurements or the type of parameters to be measured. Regarding communication requirements, such characteristics as reliability, confidentiality, integrity, authentication or non-repudiation should be considered.

- Operational procedures. The methodology to match the offers must be clearly established, including price structure, type of negotiation and time schedule of negotiation.

- $\quad$ Settlement procedures. The methodology for the settlement of the service needs to be clearly established, detailing all the terms regarding the payments that have to be done by the DR buyers and received by the DR providers. This includes the necessary variables for settlement calculations (coefficients, prices, consumptions, etc.), the calculation method or the maximum and minimum number of activations during the contract.

- Evaluation methods for baselines. The effect of a flexibility action (reduction or increment of power), as well as the impact of preparation and recover periods would be usually evaluated as the difference between the real load curve and the baseline. For that reason, the calculation of the baseline must be as accurate as possible, and it will depend on the type of process that is considered. The baseline method used for a process should be the same for the DRPV and the DRPR. If the baseline used in the evaluation of the DRPV and DRPR is not the same, the interruptible power of a particular process may be different. Some examples of existing baseline methodologies can be found in [41-43].

\subsection{Certification of Demand Response Energy Service Traders (DREST)}

A DREST provides the physical means for the proper interchange of DR services between the DRPV (customers, aggregators) and a DRRQ (TSOs, DSOs, retailers, aggregators). Thus, the prequalification document guarantees to the market agent using the services provided by this certified DREST (DRRQs) that transactions will take place in a safe and reliable way. On the other hand, the usage of a DREST will ensure to DRPVs that the DR services provided by them will be properly delivered and settled, which is essential to ensure the payments from the DRRQ.

Traditionally, this type of service has been provided by the final user of the DR or by aggregators. However, it is actually an independent activity and it could be considered as a new business which could be externalized and performed by an independent entity.

The certificate of a DREST should include the following items: 
- Validation of the knowledge and abilities of the EST on Demand Response, including the background of the EST as enterprise (previous works in this field, developed projects, etc.) and the background of the technical staff working at the EST (competence, training, skills and experience)

- Validation of the technical support of the EST, including software and hardware.

- Demonstration of the abilities of the technical staff and the capacity of the physical support of the EST in real tests.

\subsubsection{Validation of knowledge and abilities}

The certification of a company as a DREST would be based on a set of criteria which should be satisfied by the company in order to get certified. The certification is not a static process, but also must guarantee the continuous fulfilment of the company with the above-mentioned criteria, maintaining the technical competence. In addition to the aspects related to the qualification and experience of the technical staff and the required equipment, the basic criteria to be satisfied by an EST so as to be certified would include :

- The company applies appropriate methods and assessment procedures during the energy efficiency and demand response evaluation of customers.

- The company uses quality control techniques for the evaluation of the consistency of the obtained results.

- The company ensures the traceability of the measurements and the calibration according to international standards.

- The company properly communicates to the clients on the results of its activities, producing clear and accurate information and reports.

- The company has a quality system to manage its activities.

In addition to this, the company itself should demonstrate a solvent experience in energy auditing and demand response evaluation and management, independently on the individual qualifications of the current staff. In order to support this aspect, previous works on this field will be considered. In case of new companies which have no previous experience on demand response issues, more exigent requirements may be applicable to the current staff, where the need of incorporating new experts may be identified. 
Regarding the technical staff of the EST, it would be necessary to accredit that they have the necessary qualifications, abilities and experience on DR. It does not mean that all the employees, individually, must have all of the qualifications, but it is necessary that all of them, on the whole, cover the mentioned areas of knowledge. This knowledge should include, but it is not limited to, the following topics:

- Knowledge about regulation on energy efficiency and DR, as well as related to the development of the own activity (responsibility, infractions, obligations, etc.)

- Knowledge and abilities on the use of software for energy modelling, evaluation and certification

- Deep knowledge on the national electricity market and basic knowledge at international level, including the role of the different market agents, how they are linked, what the components of the final price paid by end users are and which mechanisms (regulated or market based) are used for the calculation of each one of these terms.

- Knowledge on construction, installations and renewable energies.

- Knowledge on industrial processes and applications.

- Knowledge on energy certification.

The certification of individual competence of persons is included in the norm ISO/IEC 17024:2012 [44], which could be considered for this purpose.

\subsubsection{Validation of the technical support}

The technical support includes the software and hardware necessary for the proper interchange of DR resources. The hardware used by the EST should have the following capabilities:

- Capability to store information in a secure way (database).

- Capability to communicate and interchange information between the different interested entities (consumers, utilities, system operators, aggregators, etc.) with the required speed (band width), accuracy and reliability.

- Capability to operate loads.

- Capability to measure variables. As minimum, the hardware must be able to register electrical variables, time variables associated to different events, counters to register numbers of events and other parameters which may be necessary for the evaluation of baselines (temperatures, sun radiation, etc.). 
- Capability to backup and restore in case of some problem in the system. This capability can be provided by some kind of redundant system.

Regarding the software requirements, the following characteristics should be considered:

- Software to store information in a secure data base.

- Software for communication among the different interested entities (utilities, system operators, aggregators, ...). An standard communication protocol should be used.

- Software for measurement management.

- Tools for negotiation (trading on auction basis -bids and offers-, bilateral or multilateral negotiation, etc.)

- Tools for operation which enable customers to participate as DRPVs for the system as a result of a negotiation, as well as the technical coordination between all the involved agents.

- Tools for analysis.

- Tools for settlement.

\subsubsection{Demonstration of abilities in testing}

Even if all of the previous requirements are properly addressed, it does not necessarily mean that the EST will work as specified. The previous checklist would mean that the EST has the technical capabilities but it is not a sufficient guarantee. The final stage in the certification process is the verification, where the EST has to demonstrate the real ability to perform the role assigned to it, by testing what happens in a real situation. This demonstration should be done in some kind of simulator. The first step would be the specification of the different scenarios to be tested. Based on these scenarios, the EST would facilitate the negotiation between fictitious DRPVs and the DRRQs, based on the DRPRs used by them. For each scenario it would be necessary to define in the simulator who will be selling DR and under which conditions (specification of DR providers), who will be buying DR and under which conditions (specification of DR requesters) and finally what the characteristics of the product to be traded are (specification of transactions). In a real situation, many different transactions could be happening in parallel, so that this aspect should be also considered when defining the scenarios. According to the different DRPRs, different types of negotiation should be considered (pay as bid, auction, market matching, etc.). This negotiation would be performed and different transactions may take place. Some exceptional situations should be considered, as the non-fulfilment 
of some transactions. In this last case, additional transactions would be necessary in order to guarantee a committed event (reduction or increment of power).

The effect of the performance of the different transactions would be analysed by using the tools of the EST. The impact of transactions on each DRPV and each DRRQ must be accurate and clear in terms of how results are shown to the different agents. The performed analysis would necessarily include the technical (in terms of power and energy), economic (in term of costs and benefits) and environmental (in terms of reduction of $\mathrm{CO}_{2}$ emissions) evaluation of each performed transaction. The last step would be the economic evaluation of incomes and payments to be performed by the different agents. Penalties to be paid by DR providers which have failed some event would be also included. The result of this phase should be detailed on a bill, specifying all the considered concepts that would pay or receive DRPVs and DRRQs according to their transactions.

\section{Discussion}

The lack of regulation on DR standardization makes the certification of DR activities not possible today. However, this paper works out a conceptual model to propose a procedure which might be used as a blueprint for a later certification process, the development of a standard on DR or the extension of the current available standards like ISO 50001 to allow also the certification of DR activities together with energy efficiency. Therefore, the procedure hereby proposed can be used as starting point for an iterative process where the norm for DR certification may be performed. The new norm on DR would be developed by means of an iterative process where the subsequent drafts would be progressively improved. There is not a norm on DR at this time, so that the specifications described in section 3 could be used as the starting point to initialize this iterative process. Certification bodies such as the International Organization for Standardization (ISO) or the European Committee for Standardization (CEN) would be in charge of developing this norm, which may be an extension of current available norms like ISO 50001 for the certification of energy efficiency systems. This option may be preferred especially in the part regarding to the certification of the consumer (who provides DR) as some of the requirements for consumers could be also required at this moment for the certification of energy efficiency.

The iterative process for the specification of the norm, as it is shown in Figure 6, should include the following steps: 
1. Dissemination among the potential agents interested on the trading of DR (aggregators, retailers, energy service companies, certifiers) in order to give them information and get them involved in the process.

2. Specification of a $1^{\text {st }}$ level of certification, which may include the application to all the roles except customers, which would be involved later when the framework is more mature. In this first stage in the certification process, just roles to be played by entities already familiar with DR issues would be considered. Thus, an initial framework where DR can be traded under the scope of certification may be launched. In particular, the certifications of DR Energy Service Traders (DREST), aggregators as DR Providers (DRPV) and DR products (DRPR) for the trading of DR resources from aggregators to DRRQs would be developed. In this way, all the three certificates necessary in the future DR market would start to work.

3. Specification of the capabilities required by the stakeholders in order to get certified. As a consequence of the previous step, the requirements necessary to get certified for the different roles would be highlighted, so that the entities that play such roles in the market could focus on the fulfillment of such requirements. Consequently, these specifications would be used to provide training to the stakeholders in order to empower the more relevant aspects they would need for certification purposes.

4. Specification of a $2^{\text {nd }}$ level of certification, attaining customers as providers of Demand Response (DRPVs). At this stage, the standard for the certification of DRPVs would have been partially developed but just for aggregators, considering easier to initially deal with them as they use to have previous knowledge and training on DR. Now, the standard for certification of customers as DRPVs would need to be developed.

5. Finally, based on the previous work, the recommendations for the establishment of the norm would be given to the standardization body, who would develop a proposal.

If the standardization body considers that the norm should be further worked out, a new iteration would be performed, considering as starting point the most recent proposal. The different iterations may be done according to the Standardization procedure defined in [45]. According to this document, the development and approval of a new standard may last between 3 and 5 years.

The agents who ask for the service (DRRQs) benefit from certification as it helps them to trust the services they are paying for, but this is also a significant advantage for DRPVs. It is responsibility of 
DRPVs not just to deliver the service, but also to demonstrate that they have done it. Sometimes this is a difficult task as settlement procedures are based on baselines which should be calculated in agreement to all the involved parties. Therefore, the utilization of a certified framework according to commonly accepted standards may facilitate the transaction of DR resources from all the perspectives.

Even if convenient and recommendable due to the benefits it presents, the authors consider that certification should not be compulsory for any of the three mentioned activities as it may mean an additional barrier for the transaction of DR resources, at least during this "launching stage". In opposition, the certification should be an additional guarantee which may increment the confidence in the trading of DR resources, creating a more dynamic framework for the transaction of demand services. In this context, certification should be understood as a recommendation and a convenience, but not an obligation. Thus, DRRQs would have the last word when making the decision to contract a certified or not certified DRPV to satisfy their needs. Similarly, DRPVs and DRRQs should agree if they use or not a certified DRPR for their transaction, even if the convenience of using a standard procedure arises.

\section{Conclusions}

It is commonly agreed that DR may help to improve the performance of electricity systems. However, it does not happen naturally and it needs mechanisms to be stimulated. In this context, the certification of the different activities involved in the transaction of DR resources would mean a higher confidence among the different players in the trading of demand resources, increasing the dynamism of the market and facilitating the market acceptance of DR services and products.

The lack of standards and regulation for the certification of DR is the most critical barrier found for this purpose nowadays. DR cannot be certified today. Therefore, this paper proposes a standardization procedure in order to contribute to a future DR certification for the massive utilization of demand resources once the norm is in place.

A methodology for the systematic certification of different activities related to the transaction of DR resources has been developed and it is presented here. In particular, three types of certificate have been designed so that the different activities involved in the trading of DR resources are covered. It includes the certification of the agent who provides the service (Demand Response Provider or 
DRPV), the contractual framework which states the conditions for the trading (Demand Response Product or DRPR) and the platform which enable the proper performance the transactions, including the physical means (software and hardware) and know-how (Demand Response Energy Service Trader or DREST).

This paper provides a complete overview about the benefits of certification in the framework of DR trading, developing a procedure which sets the basis for a systematic application. Regulators can find in this research the foundation for the design and specification of a norm to allow the certification of the abovementioned activities, or a further development of existing standards (like ISO 50001) where certification of DR activities would be the natural complement to energy efficiency.

\section{Acknowledgements}

This work was completed in the framework of the DRIP project (11ENV/DE/340) co-funded by the European Commission through the LIFE Environment Programme. The authors deeply thank all the participants in the project for their help and support that made possible this work.

\section{References}

[1] Klobasa M. Analysis of Demand Response and wind integration in Germany's electricity market. IET Renewable Power Generation, vol. 4, o 1, pp. 55-63, 2009.

[2] Cardell JB, Anderson CL. Targeting existing power plants: EPA emission reduction with wind and demand response. Energy Policy, vol. 4, pp. 11-23, 2015.

[3] Mahmoudi N, Saha TK, Eghbal M. Wind offering strategy in the Australian National Electricity Market: A two-step plan considering demand response. Electric Power System Research, vol. 119, pp. 187-198, 2015.

[4] Cappers P, MacDonald J, Goldman C, Ma O. An assessment of market and policy barriers for demand response providing ancillary services in U.S. electricity markets. Energy Policy, vol. 62, pp. 1031-1039, 2013.

[5] Strbac G. Demand side management: Benefits and challenges. Energy Policy, vol. 36, pp. 4419-4426, 2008. 
[6] Gils HC. Assessment of the theoretical demand response potential in Europe. Energy, vol. 67, pp. 1-18, 2014.

[7] Torriti J, Hassan MG, Leach M. Demand response experience in Europe: Policies, programmes and implementation. Energy, vol. 35, pp. 1575-1583, 2010.

[8] SEDC. A Demand Response Action Plan for Europe: Regulatory requirements and market models. Smart Energy Demand Coalition, Brussels, 2013.

[9] Alcázar-Ortega, M. Evaluation and Assessment of New Demand Response Products Based on the Use of Flexibility in Industrial Processes: Application to the Food Industry. Ph.D.

Dissertation. Dual Programme between the Polytechnic University of Valencia and the University of South Florida. Tampa, Florida, 2011.

[10] Shariatzadeh F, Mandal P, Srivastava AK. Demand response for sustainable energy systems: A review application and implementation strategy. Renewable and Sustainable Energy Reviews, vol. 45, pp. 343-350, 2015.

[11] Alcázar-Ortega M, Álvarez-Bel C, Domijan A, Escrivá-Escrivá G. Economic and environmental evaluation of customers' flexibility participating in operation markets: Application to the meat industry. Energy, vol.41, pp. 368-379, 2012.

[12] Dupont B, De Jonghe D, Olmos L, Belmans R. Demand response with locational dynamic pricing to support the integration of renewables. Energy Policy, vol. 67, pp. 344-354, 2014.

[13] Ghazvini MF, Faria P, Ramos S, Morais H, Vale Z. Incentive-based demand response programs designed by asset-light retail electricity providers for the day-ahead market. Energy, vol. 82, pp. 786-799, 2015.

[14] U.S. Department of Energy. Benefits of Demand Response in Electricity Markets and Recommendations for achieving them. A Report to the United States Congress pursuant to Section 1252 of the Energy Policy Act of 2005. February 2006. Available online: http://eetd.lbl.gov

[15] Cutter E, Woo CK, Kahrl F, Taylor A. Maximizing the Value of Responsive Load. The Electricity Journal, vol. 25, no. 7, pp. 6-16, 2012. 
[16] ISO. What's the bottom line?. International Organization for Standards, Geneve, 2012. Retrieved 08/01/2015 from http://www.iso.org/iso/bottom_line.pdf

[17] Holmberg D. Demand Response and Standards: New Role for Buildings in the Smart Grid. ASHRAE Journal, pp. B23-B28, 2011. Retrieved 11/01/2015 from http://www.bacnet.org/Bibliography/BACnet-Today-11/Holmberg-2011.pdf

[18] Piette MA, Ghatikar G, Kiliccote S, Watson D, Koch E, Hennage D. Design and operation of an Open, Interoperable Automated Demand Response Infrastructure for Commercial Buildings. Journal of Computing Science and Information Engineering, vol. 9, no. 2, 2009.

[19] Piette MA, Ghatikar G, Kliccote S, Koch E, Hennage E, Palensky P, McParland C. Open Automated Demand Response Communications Specification (Version 1.0). Public Interest Energy Research (PIER), California Energy Comission, Berkeley, California, 2009.

[20] ISO. International Standard 50001: Energy Management Systems. Requirements with guidance for use. International Organization for Standards, Geneva, 2011.

[21] Franzitta V, La Gennusa M, Peri G, Rizzo G, Scaccianoce G. Toward a European Eco-label brand for residential buildings: Holistic or by-components approaches?. Energy, vol. 36, pp. 1884-1892, 2011.

[22] Antunes $\mathrm{P}$, Carreira $\mathrm{P}$, Mira da Silva M. Towards an energy management maturity model. Energy Policy, vol. 73, pp. 803-814, 2014.

[23] The Federal Energy Regulatory Commission Staff: "Draft for comment of the National Action Plan on Demand Response". March, 2010. Available online: http://www.ferc.gov

[24] Chiu A, Ipakchi A, Chuang A, Qiu B, Brooks D, Koch E, Zhou J, Zientara MK, Precht PR, Burke R, Crowder RS. Framework for Integrated Demand Response (DR) and Distributed Energy Resources (DER) Models. NAESB \& UCAlug. September, 2009. Available online: http://osgug.ucaiug.org/

[25] Energy Information Administration Glossary. Official Energy Statistics from the U.S. Available online: $\underline{\text { http://www.eia.doe.gov }}$

[26] Mickle C. "Energy Services and DSM in the Competitive Energy Supply Market". IEE, Savoy Place, London, 1994. 3p 
[27] Goldman C, Reid M, Levy R, Silverstein A: Coordination of energy efficiency and demand response. E.O. Lawrence Berkeley Nat. Lab. January 2010.

[28] Energy Systems Integration - Demand Response. The California Energy Commission. Available online: $\underline{\text { http://www.energy.ca.gov }}$

[29] International Energy Agency (IEA) Demand Response Resources - Task XIII. Available online: http://demandresponseresources.com

[30] The birth of a EUropean Distributed EnErgy Energy Partnership that will help the large-scale implementation of distributed energy resources in Europe (EUDEEP), the European Project supported by the Sixth Framework programme for Research and Technological Development. Available online: http://www.eudeep.com

[31] Demand Response in Industrial Production (DRIP). Research Project supported by the Environment LIFE+ Programme of the European Commission. Available online: http://www.drip-project.eu

[32] EG3 Group: Regulatory Recommendations for the Deployment of Flexibility. European Commission, Smart Grid Taskforce. January 2015

[33] Ghasemi A, Saeidollah Mortazavi S, Mashhour E. Hourly demand response and battery energy storage for imbalance reduction of smart distribution company embedded with electric vehicles and wind farms. Renewable Energy, vol. 85, pp. 124-136, 2015.

[34] Cui B, Wang S, Yan C, Xue X. Evaluation of a fast power demand response strategy using active and passive building cold storages for smart grid applications. Energy Conversion and Management, vol. 102, no. 15, pp. 227-238, 2015.

[35] Yan C, Xue X, Wang S, Cui B. A novel air-conditioning system for proactive power demand response to smart grid. Energy Conversion and Management, vol. 102, no. 15, pp. 239-246, 2015.

[36] Chassin DP, Stoustrup J, Agathoklis P, Djilali N. A new thermostat for real-time price demand response: Cost, comfort and energy impacts of discrete-time control without deadband. Applied Energy, vol. 155, no. 1, pp. 816-825, 2015. 
[37] Huang Y, Tian H, Wang L. Demand response for home energy management system. International Journal of Electrical Power \& Energy Systems, vol. 73, pp. 448-455, 2015.

[38] Nolan S, O'Malley M. Challenges and barriers to demand response deployment and evaluation. Applied Energy, vol. 152, no. 15, pp. 1-10, 2015.

[39] Alcázar-Ortega M, Calpe C, Theisen T, Carbonell-Carretero FJ. Methodology for the identification, evaluation and prioritization of market handicaps which prevent the implementation of Demand Response: Application to European electricity markets. Energy Policy. Accepted for publication in August 2015.

[40] ENTSO-E. Continental Europe Operation Handbook, 2004. Retrieved 11/01/2015 from https://www.entsoe.eu/publications/system-operations-reports/operationhandbook/Pages/default.aspx

[41] PJM-MIC. PJM Empirical Analysis of Demand Response Baseline Methods. Clark Lake, Michigan, 2011.

[42] Bode J, Perry M, Morgan S, Freeman S. Assessment of settlement baseline methods for Ontario Power Authority's Commercial \& Industrial Event Based Demand Response Programs. Freeman, Sullivan \& CO., San Francisco, CA, 2010. Retrieved from http://fscgroup.com/reports/demand-response-assessment-ontario-power-authority.pdf

[43] ENERNOC. The Demand Response Baseline. EnerNOC Inc., 2009. Retrieved 12/01/2015 from http://www.enernoc.com/our-resources/white-papers/the-demand-response-baseline

[44] ISO. International Standard ISO/IEC17024:2012: Conformity assessment - General requirements for bodies operating certification of persons. International Organization for Standards, Geneva, 2012.

[45] Santodomingo R, Hamrin E, Spanka K, Bachiller R, Nordström L, Calpe C, Theisen T, Rigby S, Yunta A, García M, Johnson A, Castro F. Standard assessment regarding devices and communication architectures. EU FP7 Distributed Intelligence for Cost-Effective and Reliable Distribution Network Operation Project, 2015. Retrieved 10/03/2015 from http://www.discern.eu/datas/DISCERN_WP2-3_D2-3_3_150113_v3_0.pdf 